\title{
PROBLEMS FACED BY KITH \& KIN IN DEALING WITH THEIR PARENTS
}

\author{
CHOWDHURY SA ${ }^{1}$, JABEEN S ${ }^{2}$
}

\begin{abstract}
:
Objectives: This study was conducted to find out the problems faced by the kith and kin (children) to deal with their aged parents.

Methodology: This cross-sectional descriptive study was conducted among the rural people of Dhamrai, who had either one or both living parents. Data was collected from January to March, 2008.

Results: Three hundred respondents were interviewed; the mean age was 33.73 (S.D \pm 7.27 ) years. Most of the respondents were Muslims (92\%) and male (86\%). Majority were day labourer (37.3\%), agriculture worker (26\%) and businessman (19.3\%). Rests were service holders (11.3\%) and housewives (9\%). The educational levels of the respondents were SSC and above (41\%) while $8.6 \%$ were illiterate. Mean family size was 5.5 members with mean average monthly income 4173(S.D \pm 2007.77$)$ taka. Majority of the respondents (58.3\%) had their parents living with them and 92\% parents were dependant upon them for their living. More than half (56\%) respondents had problems due to the presence of their parents in their families. Among them, majority (63\%) had financial constrain, others were too busy with occupation (18\%), limited space in their houses (10\%), due to pressure from family members family members (9\%). More financial support (32\%), more attention (31\%), more honour (20\%) were the main expectations from their kith and kin by the parents.

Conclusion: The main problems found among the majority (56\%) of the respondents were, financial constraint (63\%), busy with occupation (18\%), limited space at home(10\%), and non co-operation from other family members(9\%).
\end{abstract}

Key Words: Kith \& Kin, Caregivers, Elderly

(J Dhaka Med Coll. 2008; 17(2) : 106-110)

\section{Introduction:}

As individuals age, they face a decline in physical and/or cognitive health, and subsequent functional limitations. As Bangladeshi's population ages and lives longer, a larger proportion of the elderly will require help and care, either from formal (paid) or informal (Kith \& Kin and friends) caregivers. At the same time, the availability of caregivers is declining. ${ }^{1}$

Decrease in fertility rates and improvement in life expectancy have led to rapid increase in the number of older people in Bangladesh with 80,000 new elderly added to the over 60 age group each year. People aged 60 years and above make up 6 percent of the total population of our country. While this percentage is small compared to developed countries due to the large size of our population, it represents approximately 8 million people. ${ }^{2}$ Furthermore, projections indicate that the number of older people will increase by 173 percent by the year 2025. The majority of older people in Bangladesh belong to the 60- 69 years age cohort in both rural and urban areas. ${ }^{3}$

Bangladesh has a long cultural and religious tradition of looking after the elderly and it is expected that families and communities will care for their own elderly members. But rapid socio economic and demographic transformations, mass poverty, declining social and religious values, influence of western culture and other factors have broken down the traditional extended family and community care system. Most of the older people in Bangladesh are suffering from some of the

1. Associate Professor, Department of Community Medicine, Dhaka Medical College, Dhaka

2. Assistant Professor, Department of Community Medicine, Dhaka Medical College, Dhaka

Correspondence : Dr. Shahjahan Ahmed Chowdhury 
basic human problems, that is, lack of sufficient income and employment opportunities, absolute poverty, senile diseases and absence of proper health and medicare facilities, exclusion and negligence, deprivation socioeconomic insecurity etc. ${ }^{4}$ Problems that are perceived and faced by the older persons in this country vary from status and residence. About $80 \%$ of the older persons in Bangladesh live in rural areas. ${ }^{2}$ They suffer the cumulative effects of a lifetime of deprivation, entering old age in a poor state of health and without savings or assets. The provision of eldercare is considered the responsibility of informal caregivers, especially children, in most Asian countries. ${ }^{5}$

A better understanding of the characteristics of adult children serving as informal caregivers, their concerns and the problems they face in caring for their elderly parents should be helpful for formulating policies and programmes benefiting the elderly. However, to date, little research has been done to explore different facets of eldercare by Kith \&Kin in Bangladesh. Data on caregivers and care-giving for the elderly from countries with similar economic and cultural profile are also lacking. Characteristics of caregivers are presented, and areas of concern and factors associated with stress among caregivers are identified. The attitudes of the adult child caregivers towards eldercare are also assessed. Based on the literature on care-giving, the gender differences were found, female caregivers were supposed to be more stressed compared to male caregivers. ${ }^{6}$

This study was a humble effort to look inside the problems faced by the off-springs (Kith \& Kin) to deal with their elderly parents and determine the relationship between two successive generations.

\section{Materials \& Methods:}

This cross sectional descriptive study was done at two unions under Dhamrai upazila of Dhaka district. Dhamrai is an upazila situated about $40 \mathrm{~km}$. North West to Dhaka city and has a population of nearly 3 lakh. The data was collected from the population living in Dhamrai, who had either one or both living parents. Data collection was done from January to March 2008. Purposive sampling technique was adapted, till achievement of a sample size of 300. A questionnaire containing structured and Semi structured questions were used for data collection. Data was collected by face to face interview. Data was processed by editing $\&$ post-coding and analyzed by SPSS version 13.0 .

\section{Result:}

Among the 300 respondents, majorities (40\%) were in the age group of 25-35 years and $36.6 \%$ belonged to $35-40$ years age group. Only $8 \%$ from 45 and above year's age group. Their mean age was 33.73 (S.D \pm 7.27 ) years. (Table-I).

\section{Table-I}

Socio-demographic characteristics of the respondents

\begin{tabular}{lcc}
\hline Variables & Frequency & Percentage \\
\hline Age in years & & \\
$>$ 15- 25 & 46 & 15.3 \\
$>$ 25- 35 & 120 & 40.0 \\
$>$ 35- 45 & 110 & 36.6 \\
$>$ >5 & 24 & 8.00 \\
Sex & & \\
Male & 258 & 86.0 \\
Female & 42 & 14.0 \\
Religion & & \\
Muslim & 276 & 92.0 \\
Hindu & 24 & 8.00 \\
Marital status & & \\
Married & 240 & 80.0 \\
Unmarried & 38 & 12.60 \\
Widow & 22 & 7.30 \\
Occupation & & \\
Day Labourer & 112 & 37.3 \\
Agriculture & 78 & 26.0 \\
Service Holder & 34 & 11.30 \\
Business & 58 & 19.3 \\
Housewife & 18 & 9.0 \\
Educational level & & \\
Illiterate & 26 & 8.6 \\
Primary Schooling & 54 & 18.0 \\
Class VI- IX & 96 & 32.00 \\
S.S.C & 70 & 23.30 \\
H.S.C & 36 & 12.00 \\
Degree Above & 18 & 6.00 \\
\hline
\end{tabular}


In regard to sex, majority (86\%) of the respondents were male. Most of the respondents were Muslim $(92 \%)$ and rest $8 \%$ were Hindus. About $80 \%$ of the respondents were married, another $12.6 \%$ were unmarried and the remaining $7.3 \%$ were widow and widower. (Table-I)

About the occupation of the respondents, 37.3\% were day labourer, 26\% were agri-worker, 19\% were businessmen and service holder $\&$ rest 20.3\% were housewives. (Table-I)

About the educational level of the respondents, our study showed only $8.6 \%$ were illiterate and $41 \%$ of the respondents were minimum SSC passed $\&$ above. (Table- 1 )

Majority (48\%) of the respondents were in the income group of Tk. 2001 -Tk.4000. Their mean monthly income was 4,173 (SD \pm 1753.235$)$ Taka. (Fig. 1)



Fig-1: Distribution of respondents by monthly family income

Most of the respondents (55.3\%) had family members between 6 to 10 members. Only 8\% had bigger family size of more than 10 members. Mean family size was 5.52 members. (Fig. 2)

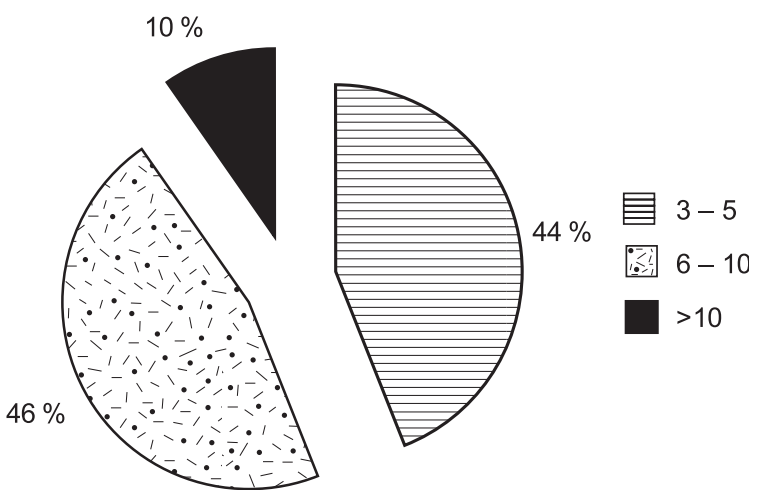

Fig.-2: Pie chart showing family members of the respondent
About $58 \%$ of the respondent's parents were living with their kith $\&$ kin, $38 \%$ of the parents were residing at their own or parental home but $92 \%$ of the parents were dependent upon their kith \& kin.

Regarding parents expectation from their Kith $\&$ Kin, multiple responses were found. Among these more financial supports (32\%), more attention (31\%), more honour (20\%) and more care $(19 \%)$ were most expected ones. (Fig-3)

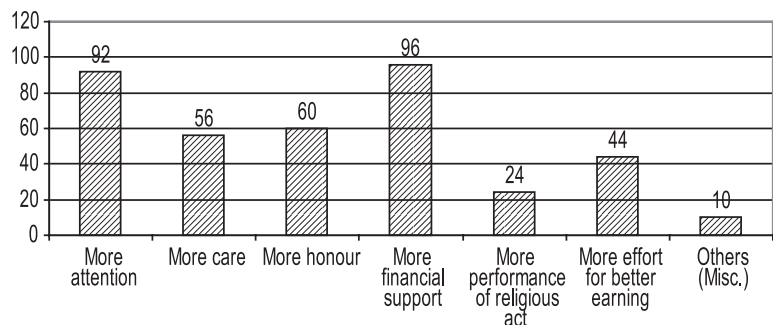

*multiple responses

Fig-3: Bar diagram showing parent's expectations from their Kith\& Kin

Nearly half of the Kith \&kin (56\%) admitted of having some problems due to the presence of their parents living with them. And rest $44 \%$ of the respondents said that they are able to look after their old parents properly. All the unmarried and widower were included in this group.

The 168 respondents who stated of facing problems due to the presence of their parents in their family, majority (63\%) admitted about financial constrain. Others were too busy with occupation (18\%), limited space in their house $(10 \%)$, due to pressure from family members' (9\%). (Fig. 4)

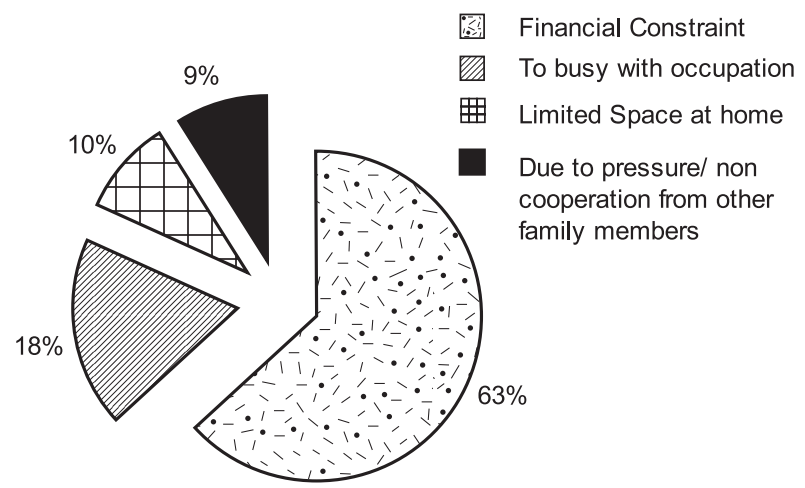

Fig- 4: Showing problems faced by Kith\& Kin in dealing with their parents $(N=168)$ 
Nearly all (98\%) Kith \& Kin felt that children should be responsible for taking care of parents in their old age. A similar response was obtained regarding the best living arrangement for the elderly.

Only $1.3 \%$ expected to receive support from the government. While a vast majority knew about old age homes, nearly everybody said they would not consider putting their parents in an old age home, the predominant reason being that it was not right to do so as children should look after their parents.

\section{Discussion:}

The present descriptive cross-sectional study was carried out among adult Kith \& Kin in rural areas under Dhamrai upazila of Dhaka district who had at least one living parents. This study was conducted with a view to find out the different type of problems faced by the respondents in dealing with their parents. However, to date, little research has been done to explore different facets of eldercare by their Kith \& Kin. Data on caregivers and care-giving for the elderly from countries with similar economic and cultural profile are also lacking. Most studies related to caregivers from Asia and other parts of the world have been conducted in developed countries and even then, mainly on caregivers of elderly with specific morbid conditions such as cancer or dementia. ${ }^{7}$

A total of 300 respondents were interviewed for this study purpose. In our study, the largest age group was between $25-35$ years $(40 \%)$ followed by the age group $35-45$ years $(36.6 \%)$. Mean age of the respondents was 33.73(SD \pm 7.27) years. More than two thirds were male and the rest were females. Our national statistics ${ }^{8}$ does not accord with this ratio, due to our cultural reasons parents prefer to stay with their sons.

Almost all were Muslims and the remaining $8 \%$ were Hindus. This figure nearly conforms to our national statistics. ${ }^{8}$ Most of the respondents were married and the remaining $20 \%$ were either unmarried or widower.

Day labourers comprised the main bulk of our respondents followed by agricultural workers and businessmen. There were some service holders and housewife too. About the educational level of the respondents, Dhamrai showed a better picture of literacy, only $8.6 \%$ were illiterate. This result is almost opposite to our national statistics. ${ }^{8}$ Most families consisted of $6-10$ members. This figure reveals that joint family norm still exists in a large proportion in the rural areas. More than half of the respondents had average monthly income of Tk. 4000 and $20 \%$ of the respondents had family income between Tk. $6000-10,000$.

Among the 300 respondents, 276 (92\%) stated that their parents were dependent upon them living either at their residence in the land inherited from their fore fathers. Only $8 \%$ of the respondent's parents did not stay with them or were not dependant upon their Kith and Kin.

Majority (56\%) of the respondents admitted that they or their family members like wife, son or daughter faced some sort of problem due to the presence of their parents at the same residence. As this question was quite a sensitive one, we suspect that many respondents may not have revealed the actual situation, especially when questioned in a public place. Figure could vary if interview was taken in privacy and properly assuring of maintaining secrecy by the interviewer. However, this result similar with studies abroad. ${ }^{7}$

More than two thirds of the parents expected more financial support, time, honour and care from their children. This study results similar with other studies. ${ }^{9}$

More than half of the Kith \&kin admitted of having some problems due to the presence of their parents living with them, economic pressure, lack of adequate space, lack of cooperation with others, and undue demand from parents were the main problems faced by them. This is the picture of most of the developing countries, where joint family norms are still present. ${ }^{9}, 10$

Only one third of the respondents said that they are able to look after their old parents properly. But two thirds stated that they were unable of taking care of their parents due to financial constraints. Almost all Kith \& Kin felt that 
children should be responsible for taking care of their parents in their old age and almost all disagreed about putting their parents in an old age home.

It is likely that some of the perceived stress or worry may be due to reasons other than eldercare, such as poverty, violence or other family problems. The lack of a comparison group of non-caregivers also limits us from determining the extent to which eldercare provision contributed to stress or worry among caregivers. Future studies should target these limitations by specifically measuring the burden and psychological impact of providing eldercare using standardized instruments. ${ }^{11}$

\section{Conclusion:}

This study was conducted among rural population revealed many aspects of generation gap between the parents with their Kith and Kin. Although the joint family structure or pattern still exists predominantly among our rural people, norms and values are diminishing gradually. Financial hardship, limited living space and modernization of the newer generation are gradually retarding the social systems and bondage in our society. Although a sensitive issue to be discussed in public, most of our respondents were free and frank to answer our questions.

The changing situation and impact of different adverse socio- economic conditions are creating problems and unhappiness between the elderly parents and their off spring. Instead of treating the elderly as a valuable resource, they are being treated as a burden mainly due to financial constrain and hardship of life.

\section{References:}

1. Care of the elderly (Training Manual) Published by BAAIGM Agargaon, Dhaka, in co-operation from WHO. $5^{\text {th }}$ Edition, August 2005. P. 1-32.

2. Rahman $\mathrm{MH}$. International year of older persons (1999) and the case of Bangladesh. Bangladesh Journal of Geriatrics. 1999; 36(1): 139-56.

3. A situation Analysis of Older People in Bangladesh. Study report conducted by Help Age International with the support of BAAIGM, BRAC \& RIC 1999.

4. Yakub AM. Healthy Ageing: Towards a society for all ages in Bangladesh. Bangladesh $\mathrm{J}$ Geriatrics. 2000; 37(182): P. 149-54.

5. Chan A. Aging in Southeast and East Asia: issues and policy directions. J Cross cultural Gerontology. 2005; 20(4): p. 269-84.

6. Chiou CJ, Chen IP, Wang HH. The health status of family caregivers in Taiwan: an analysis of gender differences. Int $\mathrm{J}$ Geriatric Psychiatry. 2005; 20(9): p. 821-26.

7. URL: http://dx.doi.org/10.1080/1744173100 3603504 Adult Children Caring for their Elderly Parents Asian Population Studies, 25 March 2010; 6(1): 83-97.

8. Statistical Pocket Book of Bangladesh 2007. Bangladesh Bureau of Statistics. Planning division, Ministry of Planning, Government of the people's republic of Bangladesh.

9. Bongaarts J, Zimmer Z. Living arrangements of older adults in the developing world: an analysis of demographic and health survey household surveys. Journals of Gerontology Series B: Psychological Sciences and Social Sciences, 2002; 57(3): p. S145-S157.

10. Wisenale J, Steven K. World Ageing Population: The coming Inter-generational Equity debate. Bangladesh J Geriatrics. 1998; 34(2): P. 74-91.

11. Deeken JF, Taylor KL, Mangan P, Yabroff KR, Ingham JM. Care for the caregivers: a review of self-report instruments developed to measure the burden, needs, and quality of life of informal caregivers', J Pain \& Symp Management. 2003; 26(4): p. 922-53. 